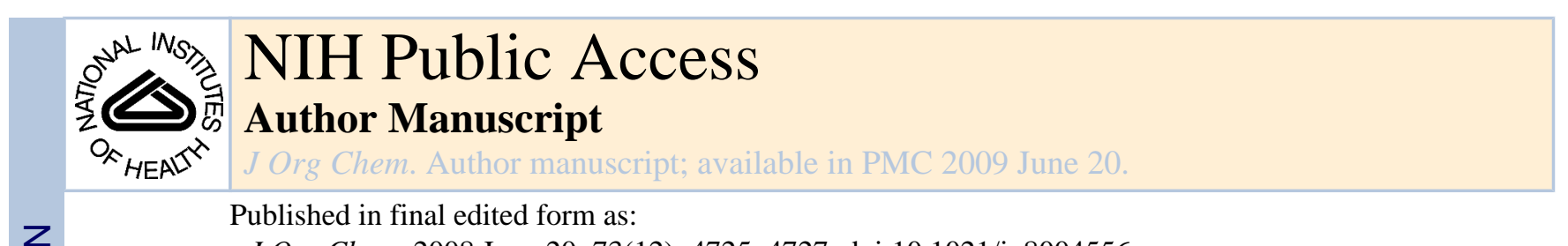

Published in final edited form as:

J Org Chem. 2008 June 20; 73(12): 4725-4727. doi:10.1021/jo8004556.

\title{
A New Method for the Synthesis of $\mathrm{H}_{4}$-BINOL
}

\author{
Lars V. Heumann and Gary E. Keck \\ Department of Chemistry, University of Utah, 315 South 1400 East RM 2020, Salt Lake City, Utah, \\ 84112-0850
}

\begin{abstract}
A method amenable to the gram scale synthesis of $(R)-\mathrm{H}_{4}$-BINOL, a derivative of $(R)$-BINOL and ligand of interest in asymmetric catalysis, is described. The key step is the net partial hydrogenation of $(R)$-BINOL made possible by prior bis-etherification of the parent BINOL.
\end{abstract}

A versatile ligand which has found widespread use in asymmetric catalysis is BINOL $(\boldsymbol{S})$-1 and $(\boldsymbol{R})-1{ }^{1}$ Both BINOL enantiomers are commercially available or can be synthesized from inexpensive starting materials in enantioenriched form $(\geq 98: 2 \mathrm{er})$, or as a racemic mixture followed by subsequent optical resolution. $1,2,3$ The BINOL enantiomers have been extensively used as chiral ligands in catalysis, especially in combination with Ti(IV) salts. The $\mathrm{BINOL} / \mathrm{Ti}(\mathrm{IV})$ system catalyzes a number of asymmetric reactions ${ }^{1}$ including allyl and Mukaiyama aldol additions to aldehydes, ${ }^{4,5}$ hetero Diels-Alder reactions, 6,7 ene-reactions, ${ }^{8}$ reduction of ketones and aldehydes, ${ }^{9,10}$ and oxidation of sulfides. ${ }^{11}$<smiles>Oc1ccc2ccccc2c1-c1c(O)ccc2ccccc12</smiles>

(S)-BINOL ((S)-1)<smiles>Oc1ccc2ccccc2c1-c1c(O)ccc2ccccc12</smiles>

$(R)$-BINOL $((R)-1)$

While the parent BINOL 1 works well as a ligand in a number of catalytic asymmetric systems, several modified versions of BINOL have been utilized in attempts to further improve such reactions. ${ }^{1 \mathrm{~b}}$ One modification has been achieved by a formal partial hydrogenation of BINOL 1 to give $\mathrm{H}_{4}$-BINOL 2 and $\mathrm{H}_{8}$-BINOL 3 . 
<smiles>Oc1ccc2c(c1-c1c(O)ccc3ccccc13)CCCC2</smiles>

$(R)-\mathrm{H}_{4}$-BINOL $((R)-2)$<smiles>Oc1ccc2c(c1-c1c(O)ccc3c1CCCC3)CCCC2</smiles>

$(R)-\mathrm{H}_{8}$-BINOL ((R)-3)

Both the $\mathrm{H}_{4}$-BINOL 2 and $\mathrm{H}_{8}$-BINOL 3 ligands have been shown to work well in a number of catalytic asymmetric reactions ${ }^{12}$ including the addition of alkylzinc and alkylaluminum reagents to aldehydes and the Hetero-Diels-Alder addition using Danishefsky's diene. ${ }^{13}$ In addition, the enantioselectivities obtained with these ligands surpassed those observed for reactions using the parent BINOL $\mathbf{1}$ as a ligand.

Recently, we were interested in examining the use of $\mathrm{H}_{8}$-BINOL and $\mathrm{H}_{4}$-BINOL in an asymmetric vinylogous Mukaiyama aldol reaction catalyzed by $\mathrm{BINOL} / \mathrm{Ti}(\mathrm{OiPr})_{4}(\mathrm{BITIP}) .{ }^{5 \mathrm{a}}$ While $\mathrm{H}_{8}$ - $\mathrm{BINOL}$ is commercially available, to our knowledge, $\mathrm{H}_{4}$-BINOL is not. Moreover, the only published method for the preparation of $\mathrm{H}_{4}$-BINOL involves heating a mixture of $\mathrm{Ni}$ / Al alloy, $\mathrm{NaOH}, \mathrm{H}_{2} \mathrm{O}, i \mathrm{PrOH}$ and $\mathrm{MOM}_{2}$-BINOL to $80^{\circ} \mathrm{C}$ for $24 \mathrm{~h}$ at a concentration of 3 $\mu \mathrm{mol} / \mathrm{L}$ (ca. $1 \mathrm{~L}$ of solvent for $1 \mathrm{~g}$ of substrate) followed by protective group removal, including chromatographic purification following each operation. ${ }^{14}$ The prospect of using the above process for a gram to multigram scale synthesis of $\mathrm{H}_{4}$-BINOL $\mathbf{3}$ led us to examine the development of an alternative procedure.

$\mathrm{H}_{8}$-BINOL 3 has been accessed from BINOL 1 using several different hydrogenation conditions; ${ }^{15,16}$ among these, a straightforward procedure appeared to be the partial hydrogenation of either BINOL enantiomer 1 using Adam's catalyst $\left(\mathrm{PtO}_{2} \cdot\left(\mathrm{H}_{2} \mathrm{O}\right)_{\mathrm{x}}\right)$ in $\mathrm{AcOH}$, under three atmospheres of $\mathrm{H}_{2}$, which provides enantiomerically pure $\mathrm{H}_{8}$-BINOL. 16

We initially hypothesized that $\mathrm{H}_{4}$-BINOL 2 could be a possible intermediate in the hydrogenation of BINOL 1 using Adam's catalyst in AcOH. Therefore, we decided to perform this hydrogenation under only one atmosphere of $\mathrm{H}_{2}$ with the intention of intercepting $\mathrm{H}_{4}$ BINOL 2. However, in the event, only BINOL 1 and $\mathrm{H}_{8}$-BINOL 3 could be detected by TLC or HPLC analysis.

We next considered the use of a sterically demanding substituent on one of the two BINOL hydroxyls.

The ' $i$ Pr' group was selected as a bulky substituent and introduced to BINOL $(\boldsymbol{R})-\mathbf{1}$ with $\mathrm{K}_{2} \mathrm{CO}_{3}$ in dry acetone (Scheme 1). The hydrogenation was carried out in $\mathrm{AcOH}$ using Adam's catalyst and one atmosphere of $\mathrm{H}_{2}$. The ${ }^{1} \mathrm{H}$ NMR of the crude product revealed that, as expected, $i \mathrm{Pr}-\mathrm{H}_{8}$-BINOL $(\boldsymbol{R})-7$ had formed as a byproduct. In addition, two other isomers were present which were later identified as compounds 5 and $\mathbf{6}$. Deprotection of the crude mixture using $\mathrm{BBr}_{3}$ yielded $\mathrm{H}_{4}$-BINOL $(\boldsymbol{R})-2$ and $\mathrm{H}_{8}$-BINOL $(\boldsymbol{R})-3$. ${ }^{17}$

The isolation of some $\mathrm{H}_{4}$-BINOL $(\boldsymbol{R})-\mathbf{2}$ was encouraging, and we decided to investigate the influence of a second ' $i \mathrm{Pr}$ ' ether (Scheme 2). The hydrogenation of $i \operatorname{Pr}_{2}-\operatorname{BINOL}(\boldsymbol{R})-\mathbf{8}$ using the same conditions was slower compared to the hydrogenation of $i \operatorname{Pr}-\mathrm{BINOL}(\boldsymbol{R})-\mathbf{4}$. TLC analysis revealed the initial formation of $i \mathrm{Pr}_{2}-\mathrm{H}_{4}$-BINOL; the appearance of $i \mathrm{Pr}_{2}-\mathrm{H}_{4}-\mathrm{BINOL}$ was followed by the development of $i \mathrm{Pr}_{2}-\mathrm{H}_{8}$-BINOL. The reaction was worked up and the 
crude material deprotected with $\mathrm{BBr}_{3}$ yielding $\mathrm{H}_{4}$ - $\mathrm{BINOL}(\boldsymbol{R})-\mathbf{2}$ as the major product together with some $\mathrm{H}_{8}$-BINOL $(\boldsymbol{R})-3$. See Scheme II.

The overreduction yielding $\mathrm{H}_{8}$-BINOL $(\boldsymbol{R})-\mathbf{3}$ was undesired but appears to be inherent to this hydrogenation. The amount of $\mathrm{H}_{8}$-BINOL $(\boldsymbol{R})-\mathbf{3}$ could be kept low by monitoring the reaction progress and stopping the hydrogenation at the first appearance of $i \mathrm{Pr}_{2}-\mathrm{H}_{8}-\mathrm{BINOL}$. We were able to obtain yields of up to $82 \%$ of $\mathrm{H}_{4}$-BINOL $(\boldsymbol{R})$-2 following this hydrogenationdeprotection sequence (see Experimental Section and Supporting Information). ${ }^{18}$ In practice, the reduction was monitored by HPLC using small neutralized and filtered aliquots of the reaction mixture, and the reaction was terminated at $50 \%$ conversion.

Adam's catalyst appears to be unique in its ability to catalyze this hydrogenation. ${ }^{19}$ A number of other heterogeneous catalysts were tested for their ability to hydrogenate $i \mathrm{Pr}_{2}-\mathrm{BINOL}$

$(\boldsymbol{R})-\mathbf{8}$; however, an $8 \%$ yield of $i \mathrm{Pr}_{2}-\mathrm{H}_{4}-\mathrm{BINOL}$ using $5 \% \mathrm{Rh} / \mathrm{C}$ was found to be the best result. 20

The preparation of $\mathrm{H}_{4}-\mathrm{BINOL}(\boldsymbol{R})-\mathbf{2}$ using $i \mathrm{Pr}_{2}-\mathrm{BINOL}(\boldsymbol{R})-\mathbf{8}$ and Adam's catalyst represents a convenient method to access this interesting ligand. The hydrogenation is operationally simple and is amenable for gram-scale syntheses of $\mathrm{H}_{4}$-BINOL $(\boldsymbol{R})-\mathbf{2}$. This preparation uses a much higher substrate concentration $(0.1 \mathrm{M}$ vs $3 \mu \mathrm{M})$ than the only other available method, and only one final chromatographic purification is required, as opposed to two. The formation of $i \mathrm{Pr}_{2}-\mathrm{H}_{8}-\mathrm{BINOL}$ as a byproduct appears to be inherent to the reaction conditions; however, this side reaction can be suppressed by stopping the hydrogenation at the first appearance of $i \operatorname{Pr}_{2}-$ $\mathrm{H}_{8}$-BINOL.

\section{Experimental Section}

\section{Preparation of $(R)-5,6,7,8$-tetrahydro-[1,1']binaphthalenyl-2,2'-diol $(R)-2^{14}$ and $(R)-5,6,7,8,5^{\prime}$, 6',7',8'-octahydro-[1,1']binaphthalenyl-2,2'-diol $(R)-3 .{ }^{15,16}$}

To a $500 \mathrm{~mL}$ round-bottom flask equipped with a stirbar at room temperature were added $(R)$ $i \operatorname{Pr}_{2}$-BINOL $(\boldsymbol{R})-8(1.00 \mathrm{~g}, 2.70 \mathrm{mmol}, 1.00 \mathrm{eq})$, glacial acetic acid $(27 \mathrm{~mL}, 0.10 \mathrm{M})$, and $\mathrm{PtO}_{2} \cdot\left(\mathrm{H}_{2} \mathrm{O}\right)_{\mathrm{x}}(0.066 \mathrm{~g}, 0.27 \mathrm{mmol}, 0.10 \mathrm{eq})$. The flask was flushed with a stream of dry nitrogen and equipped with an adapter with a valve and a balloon filled with hydrogen. The valve was opened and the mixture exposed to a hydrogen atmosphere (balloon, ca. $1 \mathrm{~atm}$ ). The progress of the reaction was closely monitored by TLC and/or HPLC since reaction time and composition were found to be strongly dependent on the activity of the active catalyst which was generated in situ. After $5 \mathrm{~h}$ the flask was flushed with a dry stream of nitrogen and the mixture diluted with a solution of saturated aqueous $\mathrm{NaOH}(14 \mathrm{~mL})$ followed by slow addition of saturated aqueous $\mathrm{NaHCO}_{3}$ solution $(200 \mathrm{~mL})$ until evolution of gas stopped. The mixture was extracted with 50\% EtOAc/hexanes (100, 150 and $200 \mathrm{~mL}$ ), and the organic phase washed with water $(50$ and $100 \mathrm{~mL})$ and brine $(50 \mathrm{~mL})$, dried over $\mathrm{Na}_{2} \mathrm{SO}_{4}$, then filtered and concentrated under reduced pressure. The residue was dissolved in $\mathrm{CH}_{2} \mathrm{Cl}_{2}(50 \mathrm{~mL})$ and transferred into a $250 \mathrm{~mL}$ round-bottom flask equipped with a stirbar, rubber septum, and nitrogen inlet. Boron tribromide $(2.5 \mathrm{~mL}, 27 \mathrm{mmol}, 10.0 \mathrm{eq})$ was added at room temperature followed after $10 \mathrm{~min}$ by slow addition of aqueous $\mathrm{NaOH}$ solution $(0.75 \mathrm{M}, 50 \mathrm{~mL})$. The organic phase was washed with saturated aqueous $\mathrm{NH}_{4} \mathrm{Cl}$ solution $(50 \mathrm{~mL})$, water $(50$ and $100 \mathrm{~mL})$ and brine $(50 \mathrm{~mL})$, then dried over $\mathrm{Na}_{2} \mathrm{SO}_{4}$, filtered and concentrated under reduced pressure. The residue was purified by flash chromatography on a $3 \times 21 \mathrm{~cm}$ silica gel column eluting with a solvent gradient from $1 \%$ through $5 \%$ acetone/hexanes. The product containing fractions were concentrated to give $(R)-\mathrm{H}_{4}$ - $\mathrm{BINOL}(\boldsymbol{R})-2(0.644 \mathrm{~g}, 2.22 \mathrm{mmol}, 82 \%$ yield $)$ and $(R)-\mathrm{H}_{8^{-}}$ BINOL $(\boldsymbol{R})-3$ (127 mg, $0.431 \mathrm{mmol}, 16 \%$ yield) as white solids. Analytical data for 2: mp 128

${ }^{\circ} \mathrm{C}$ (lit14 mp 131-133), $\mathrm{R}_{f} 0.23$ (25\% EtOAc/hexanes), $[\alpha]_{\mathrm{D}}^{20}+40.2$ (c 1.01, THF), (lit14 
$\left.[\alpha]_{\mathrm{D}}^{25}+40.4,(c 0.98, \mathrm{THF})\right) ; 300 \mathrm{MHz}{ }^{1} \mathrm{H} \mathrm{NMR}\left(\mathrm{CDCl}_{3}\right) \delta 7.90-7.83(\mathrm{~m}, 2 \mathrm{H}), 7.42-7.23(\mathrm{~m}$, $4 \mathrm{H}), 7.12(\mathrm{~d}, J=8.3 \mathrm{~Hz}, 1 \mathrm{H}), 6.89(\mathrm{~d}, J=8.3 \mathrm{~Hz}, 1 \mathrm{H}), 5.23(\mathrm{~s}, 1 \mathrm{H}), 4.54(\mathrm{~s}, 1 \mathrm{H}), 2.84-2.72$ $(\mathrm{m}, 2 \mathrm{H}), 2.33-2.05(\mathrm{~m}, 2 \mathrm{H}), 1.79-1.55(\mathrm{~m}, 4 \mathrm{H}) ; 75 \mathrm{MHz}{ }^{13} \mathrm{C}$ NMR $\left(\mathrm{CDCl}_{3}\right) \delta$ 152.4, 152.0, 138.5, 133.1, 131.6, 131.0, 130.4, 129.5, 128.5, 127.5, 124.1, 123.9, 117.7, 117.5, 113.4, 112.6, 29.4, 27.2, 23.1, 23.1; $75 \mathrm{MHz}$ DEPT $\left(\mathrm{CDCl}_{3}\right) \delta \mathrm{CH}_{2}: 29.4,27.2,23.1$ (2). CH: 131.6, 131.0, 128.6, 127.5, 124.1, 123.9, 117.7, 113.4. C: $152.4,152.0,138.5,133.1,130.4,129.5,117.5$, 112.6; IR (neat) 3478, 3414, 3057, 2929, 2857, 1619, 1595, 1475, 1389, 1189, 1147, 817, 752 $\mathrm{cm}^{-1}$; HRMS (ESI/APCI) Calcd for $\mathrm{C}_{20} \mathrm{H}_{19} \mathrm{O}_{2} \mathrm{~m} / \mathrm{z}(\mathrm{M}+\mathrm{H}): 291.1385$. Found: 291.1390. Only the (R) enantiomer was detected by HPLC analysis using a chiral column (see Supporting Information).

\section{Supplementary Material}

Refer to Web version on PubMed Central for supplementary material.

\section{Acknowledgments}

Financial support was provided by the National Institutes of Health through grant GM-29861.

\section{References}

(1). (a) For a recent comprehensive review on the preparation and the use of BINOL as a ligand, see:Brunel JM. Chem. Rev 2005;105:857. [PubMed: 15755079] and references therein.(b) For a recent review on modified BINOL derivatives with some information on the parent BINOL, see:Chen Y, Yekta S, Yudin AK. Chem. Rev 2003;103:3155. [PubMed: 12914495] and references therein.

(2)(a). Brussee J, Groenendijk JLG, Koppele JM, Jansen ACA. Tetrahedron 1985;41:3313. (b) Brussee J, Jansen ACA. Tetrahedron Lett 1983;24:3261.

(3)(a). For oxidative coupling of 2-naphthol, see:Villemin D, Sauvaget F. Synlett 1994:435. (b) Love BE, Bills RA. Synth. Commun 2002;32:2067. (c) Ji SJ, Lu J, Zhu X, Yang J, Lang JP, Wu L. Synth. Commun 2002;32:3069.For the optical resolution of racemic BINOL, see: (d) Colonna S, Re A, Wynberg H. J. Chem. Soc., Perkin Trans. 1 1981:547. (e) Cai D, Hughes DL, Verhoeven TR, Reider P. Tetrahedron Lett 1995;36:7991.

(4)(a). Keck GE, Krishnamurthy D, Roush WR, Reilly ML. Org. Synth 1998;75:12. (b) Keck GE, Geraci LS. Tetrahedron Lett 1993;34:7827. (c) Keck GE, Tarbet KH, Geraci LS. J. Am. Chem. Soc 1993;115:8467. (d) Keck GE, Krishnamurthy D, Grier MC. J. Org. Chem 1993;58:6543.

(5)(a). Heumann LV, Keck GE. Org. Lett 2007;9:4275. [PubMed: 17887693] (b) Keck GE, Krishnamurthy D. J. Am. Chem. Soc 1995;117:2363.

(6)(a). Terada M, Mikami K, Nakai T. Tetrahedron Lett 1991;32:935. (b) Mikami K, Terada M, Motoyama Y, Nakai T. Tetrahedron: Asymmetry 1991;2:643.

(7)(a). Keck GE, Krishnamurthy D. Synth. Commun 1996;26:367. (b) Keck GE, Li X-Y, Krishnamurthy D. J. Org. Chem 1995;60:5998.

(8)(a). Mikami K, Terada M, Nakai T. J. Am. Chem. Soc 1989;111:1940. (b) Mikami K, Terada M, Nakai T. J. Am. Chem. Soc 1990;112:3949.

(9). Keck GE, Krishnamurthy D. J. Org. Chem 1996;61:7638. [PubMed: 11667705]

(10). Imma H, Mori M, Nakai T. Synlett 1996:1229.

(11). Komatsu N, Hashizume M, Sugita T, Uemura S. J. Org. Chem 1993;58:4529.

(12)(a). Iida T, Yamamoto N, Matsunaga S, Woo H-G, Shibasaki M. Angew. Chem., Int. Ed 1998;37:2223. (b) Lin Y-M, Fu I-P, Uang B-J. Tetrahedron: Asymmetry 2001;12:3217. (c) Kim JG, Camp EH, Walsh PJ. Org. Lett 2006;8:4413. [PubMed: 16986913]

(13)(a). Wang B, Feng X, Huang Y, Liu H, Cui X, Jiang Y. J. Org. Chem 2002;67:2175. [PubMed: 11925225] (b) Chan ASC, Zhang F-Y, Yip C-W. J. Am. Chem. Soc 1997;119:4080. (c) Zhang FY, Chan ASC. Tetrahedron: Asymmetry 1997;8:3651. (d) Long J, Hu J, Shen X, Ji B, Ding K. J. Am. Chem. Soc 2002;124:10. [PubMed: 11772048] 
(14). Shen X, Guo H, Ding K. Tetrahedron: Asymmetry 2000;11:4321.

(15)(a). Guo H, Ding K. Tetrahedron Lett 2000;41:10061. (b) Karam O, Martin-Mingot A, Jouannetaud M-P, Jacquesy J-C, Cousson A. Tetrahedron 2004;60:6629. (c) Korostylev A, Tararov VI, Fischer C, Monsees A, Boerner A. J. Org. Chem 2004;69:3220. [PubMed: 15104470]

(16)(a). Cram DJ, Helgeson RC, Peacock SC, Kaplan LJ, Domeier LA, Moreau P, Koga KM, Mayer J, Chao Y, Siegel MG, Hoffman DH, Sogah GDY. J. Org. Chem 1978;43:1930. (b) McDougal NT, Trevellini WL, Rodgen SA, Kliman LT, Schaus SE. Adv. Synth. Catal 2004;346:1231. (c) Reetz M, Merk C, Naberfeld G, Rudolph J, Griebenow N, Goddard R. Tetrahedron Lett 1997;38:5273.

(17). Sala T, Sargent MV. J. Chem. Soc., Perkin Trans. 1 1979:2593.

(18). Using the same batch of Adam's catalyst, the activity of the reduced Adam's catalyst was found to be somewhat variable. Adam's catalyst is a precatalyst consisting of $\mathrm{PtO}_{2}$, and its exposure to $\mathrm{H}_{2}$ generates the active $\mathrm{Pt}(0)$-catalyst in situ. As a rule of thumb, the generation of fine black particles resulted in a highly active catalyst whereas the reaction was found to be slow when the particles stuck to the wall of the flask or bonded together to form small spheres

(19). The Catalyst Technical Handbook - Be Selective. Johnson Matthey Catalysts; West Deptford, NJ: 2005.

(20). The list of catalysts examined for the hydrogenation of $i \operatorname{Pr}_{2}-\mathrm{BINOL}(\boldsymbol{R})-8$ included $0.5 \% \mathrm{Pt} /$ $\mathrm{Al}_{2} \mathrm{O}_{3}$ pellets (5\% yield), $20 \% \mathrm{Pd}(\mathrm{OH})_{2} / \mathrm{C}$ (Pearlman's catalyst, $4 \%$ yield), $5 \% \mathrm{Rh} / \mathrm{Al}_{2} \mathrm{O}_{3}$ powder (3\% yield), $5 \% \mathrm{Pd} / \mathrm{C}$ (1\% yield), $5 \% \mathrm{Pt} / \mathrm{C}$ wet (2\% yield), $5 \% \mathrm{Ru} / \mathrm{C}(\mathrm{NR}), 0.5 \% \mathrm{Ru} / \mathrm{MgO}$ pellets (NR), $5 \% \mathrm{Pd} / \mathrm{BaSO}_{4}$ unreduced (NR), $5 \% \mathrm{Pd} / \mathrm{BaSO}_{4}$ reduced (NR), $5 \% \mathrm{Pd} / \mathrm{C} / \mathrm{Pb}$ (Lindlar's catalyst, NR), Pd(IV)oxide (NR), Rh(IV)oxide (NR), and Pt black (NR) (yields determined by HPLC). 


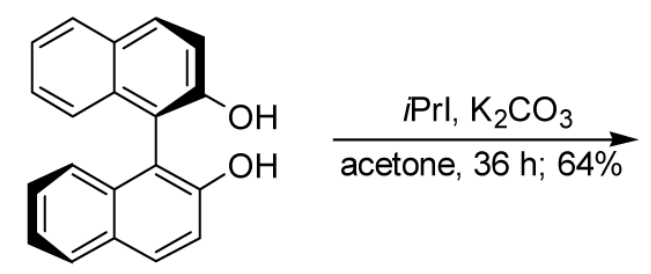

(R)-1<smiles>CC(C)Oc1ccc2ccccc2c1-c1c(O)ccc2ccccc12</smiles>

(R)-4

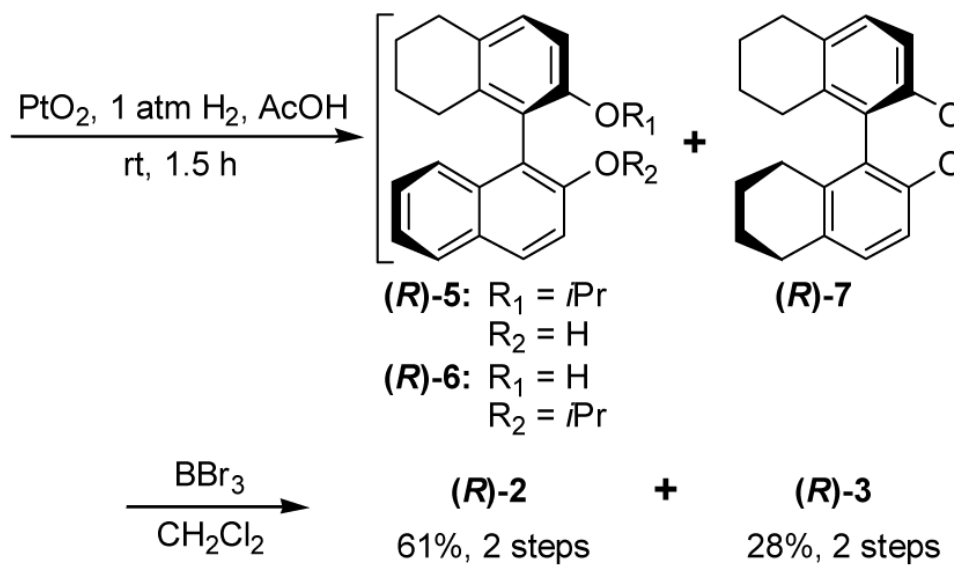

SCHEME 1. Results with $i$ Pr-BINOL (R)-4 


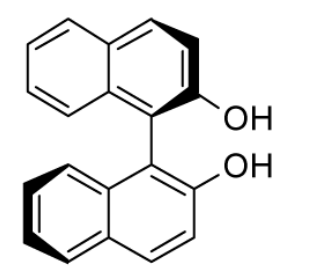

(R)-1

1) $\mathrm{PtO}_{2}, \mathrm{H}_{2}, \mathrm{AcOH}$,

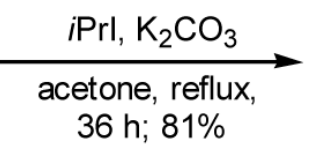

$36 \mathrm{~h} ; 81 \%$

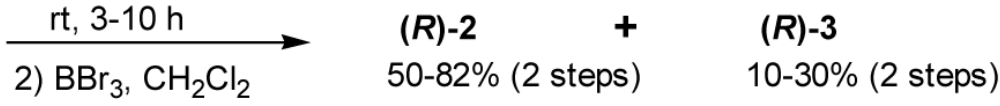

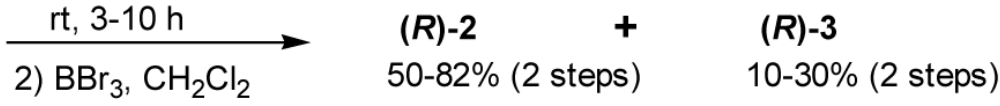

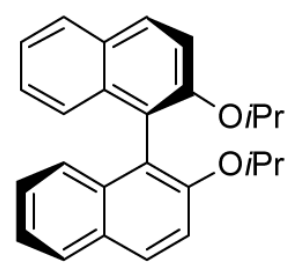

(R)-8

SCHEME 2. Synthesis of $\mathrm{H}_{4}$-BINOL $(R)-2$ 